\section{Comparative Consumer Perspectives on Eco-friendly and Insect Management Practices on Floriculture Crops}

\author{
Kristin L. Getter ${ }^{1,4}$, Bridget K. Behe ${ }^{2}$, and Heidi Marie Wollaeger ${ }^{3}$
}

ADDITIONAL INDEX WORDS. bedding plants, environmentally friendly, purchasing habits, conjoint analysis, likelihood-to-buy

SUMMARY. Declining bee populations has garnered media attention, which has pressured plant retailers to ask or demand the reduction or elimination of neonicotinoid insecticide use in greenhouse production. This study investigated consumer perspectives on eco-friendly ornamental plant production practices in combination with a variety of insect management practices. Data from an online study were collected from 1555 Americans in May 2015. Over half (55\%), nearly half $(48.2 \%)$, and more than $30 \%$ of the participants felt that "bees are not harmed," "better for the environment," or "plants that attract bees," respectively, was a characteristic of bee-friendly insect management practices. The latter group erroneously confused bee-friendly insect management practices with plants that are a potential food source for bees. When asked to rate various insect management plant production practices on a five-point Likert scale, consumer mean scores were positive (defined here as $\mathbf{3 . 5}$ to 5.0) for "plants grown using bee-friendly insect management practices," "plants grown using insect management strategies that are safe for pollinators," "plants grown using best insect management practices to protect pollinators," and "plants grown using insect management practices that leaves no insecticide residue on the plant." Plant species accounted for $31.6 \%$ of the decision to purchase the plant, followed by price $(25.1 \%)$, insect management strategy $(23.3 \%)$, and eco-friendly practices $(20.1 \%)$ that was similar to prior published findings. Analyses showed that plants labeled as "grown using beefriendly insect management practices" were worth $\$ 0.26, \$ 0.26, \$ 0.89$, and $\$ 1.15$ more than plants labeled as "grown in a sustainably produced potting soil/mix," "grown using recycled/recaptured water," "grown using protective neonicotinoid insecticides," and "grown using traditional insect management practices," respectively. In addition, plants labeled as "grown using best insect management practices to protect pollinators" were worth $\$ 0.10, \$ 0.10, \$ 0.73$, and $\$ 0.99$ more than plants labeled as "grown in a sustainably produced potting soil/mix," "grown using recycled/recaptured water," "grown using protective neonicotinoid insecticides," and "grown using traditional insect management practices," respectively. Thus, selected insect management strategies were valued more, on average, than ecofriendly production practices.

$\mathrm{H}$ oneybee (Apis mellifera), bumblebee (Bombus sp.), and other solitary bee populations have declined dramatically in the last 50 years from a combination of factors including: habitat loss, dietary stresses, climate change, pesticide exposures, and exposure to mites, parasites, and pathogens including varroa mite (Varroa

Department of Horticulture, Michigan State University, 1066 Bogue Street, East Lansing, MI 48824

We gratefully acknowledge funding from Project GREEEN. This project was supported by the USDA National Food and Agriculture, Hatch Project Number MICL 02085 , and by Michigan State University AgBioResearch.

${ }^{1}$ Floriculture Outreach Specialist

${ }^{2}$ Professor

${ }^{3}$ Greenhouse Extension Educator

${ }^{4}$ Corresponding author. E-mail: getterk@msu.edu. destructor) and nosema disease (Nosema ceranae) (Doublet et al., 2015; Goulson et al., 2015). Recently, neonicotinoid insecticides, a class of insecticides that act as neurotoxins to control a wide variety of crop pests, were shown to be a contributing factor to bee decline (Doublet et al., 2015; Goulson, 2013; Goulson et al., 2015; Pisa et al., 2015). As a result of emerging scientific evidence and social and political pressures, retailers are asking or demanding that plant producers reduce or eliminate the use of neonicotinoid insecticides in ornamental plant production. According to a nationwide study performed by Wollaeger et al. (2015), despite increasing media inof American consumers did not formation on bee decline, the majority understand what neonicotinoid insecticides were and discounted plants labeled as "neonicotinoid-free." Furthermore, when ornamental plants were labeled with insect management methods, consumers valued those methods as much or more than plant price and as much or less than plant species. Labeling plants as "beefriendly" produced a greater perceived economic value compared with plants labeled with "neonicotinoid-free," "grown with use of beneficial insects" or "grown with traditional insect management" (Wollaeger et al., 2015).

Research showed that some consumers have a greater willingness to pay for some insect management practices including those that are pesticidefree, grown with biological control, or biorational spray programs (Grygorczyk et al., 2014; Jetter and Paine, 2004; Olson et al., 1995; Wollaeger et al., $2015)$. In addition, some consumers are willing to pay a premium for plants grown with environmentally friendly practices. For example, consumers were willing to pay a premium for containers with a smaller rather than larger carbon footprint (Yue et al., 2010). In another study, consumers were reportedly more interested in purchasing plants that were produced using energy-saving production techniques than those labeled sustainably grown or grown with water-saving practices (Behe et al., 2013). The container type (compostable, conventional, plantable, or recyclable) and production practice (conventional, energysaving, sustainable, or water-saving) were similarly important to consumers.

In the present study, our goal was to develop a more holistic consumer perspective to better understand consumer perceptions and willingness to pay a price premium for floriculture crops grown using different pest management practices (grown using bee-friendly insect management practices, best insect management practices to protect pollinators, protective neonicotinoid insecticides, or traditional insect management practices) and eco-friendly production practices (grown in a container made from recycled materials, in a sustainably produced potting soil/mix, using recycled/recaptured water, or using traditional plant production methods). The combination 
of these two attributes represents a broader and, perhaps, more realistic set of attributes consumers might encounter and evaluate when purchasing plants. We investigated consumer's perception of, and preferences for, plants grown with these insect management and eco-friendly production methods. We explored the importance of pest management practices relative to eco-friendly production practices, plant species, and price in consumer's purchasing decisions.

\section{Materials and methods}

Survey Development. An Internet survey was developed in Qualtrics (Provo, UT) and was administered from 11 to 13 May 2015. Potential survey respondents were contacted from a pool maintained by Global Market Insite Institute (GMI; Bellevue, WA) and invited to participate in the survey. Respondents were paid in points to redeem prizes through GMI. Both the firm and their panel have been used to recruit subjects for prior online studies involving horticultural products (Behe et al., 2010, 2013; Getter and Behe, 2013; Wollaeger et al., 2015).

The survey collected data from consumers who had made a live plant purchase in the past 12 months. The survey aimed to collect at least 1500 responses distributed across the continental United States. In compliance with federal law, no participants under the age of 18 were invited to participate and the survey protocol and instrument were approved by the university's institutional review board (IRB) for research involving human subjects (IRB no. xl4-323e). The survey included multiple-choice (single and multiple answer) and rating (using a five- or seven-point Likert scale) question types. With the exception of an initial consent-toparticipate question and a question to determine if the participant had purchased a live plant within the last 12 months, all respondents had the option to not respond to any subsequent questions. Questions were grouped into five categories: likelihood-to-buy, characteristics and connotations of insect management practices, importance of plant attributes in purchasing decisions, and demographic characteristics of the respondents.
Each likelihood-to-buy question was framed by showing subjects a picture of a floriculture product in a 4inch $(10.2 \mathrm{~cm})$ container with text of the price, description of the greenpractices, and description of the greenhouse eco-friendly production practices (Table 1). The participant was then asked "How likely would you be to purchase this plant?" and asked to respond with a whole unit on the Likert scale of 1 (very unlikely) to 5 (very likely). The second set of questions (characteristics and connotations of insect management practices) asked "Which of the following do you consider to be characteristic of plants that are grown using" either "bee-friendly insect management practices," "traditional insect management practices," "best insect management practices to protect pollinators," or "protective neonicotinoid insecticides? (Choose all that apply)." Participants could respond with any of the 34 response options, including "I do not know." These agement practices were developed by the researchers in response to the results reported in Wollaeger et al. (2015) and to one commercially available tag in the 2015 season that stated, "This plant is protected from problematic aphids, whiteflies, beetles, mealy bugs, and other unwanted pests by neonicotinoids." One question also evaluated the connotations associated with labeling plants with their insect management practices. Participants were asked to rank on house pest management production four phrases describing insect man-

a scale of 1 (means something very negative) to 5 (means something very positive) seven pest management labeling wording. The third block of questions (importance of plant attributes in purchasing decisions) asked the participant what characteristics are important to them when purchasing an ornamental live plant. The final block of questions asked about the respondents' demographic information including age, gender, ethnicity, marital status, education, and household income.

Conjoint development. Conjoint analysis was used to understand the implicit effects of plant attributes on consumer product choice decisions and is not uncommon in consumer horticulture research (Behe et al., 2005a, 2005b, 2013; Hall et al., 2010; Wollaeger et al., 2015; Zagaden et al., 2008). This statistical method determines preferences of participants for hypothetical products about a given set of attributes and was used here on the likelihood-to-buy questions (Kuhfeld, 2010). Conjoint analysis defines overall preference for a particular product, in this case ornamental plants with varying price points, insect management strategies, and eco-friendly production methods, as the sum of the partworths (also termed utilities) for each factor level (Hartigan, 1975; van Gaasbeek and Bouwman, 1991). In other words, the part-worth utility shows the relative value of one level of an attribute to another, whereas the relative importance shows the importance among attributes.

Table 1. The likelihood to purchase attributes (species, price, insect management strategy, and eco-friendly production method) with their respective levels for an Internet survey querying consumers (who had purchased live plants in the past 12 mo.) perspectives on eco-friendly ornamental plant production practices in combination with a variety of insect management practices.

\begin{tabular}{ll}
\hline Attribute & \multicolumn{1}{c}{ Levels } \\
\hline $\begin{array}{l}\text { Species } \\
\text { Price for a 4-inch } \\
(10.2 \mathrm{~cm}) \text { pot }\end{array}$ & $\$ 1.99, \$ 2.49, \$ 2.99, \$ 3.49$ \\
Insect management & Grown using bee-friendly insect \\
& management practices, best insect \\
& management practices to \\
& protect pollinators, protective neonicotinoid \\
& insecticides, or traditional insect management practices \\
& Grown in a container made from recycled materials, \\
Eco-friendly practice & in a sustainably produced potting soil/mix, using \\
& recycled/recaptured water, or using traditional \\
& plant production methods \\
\hline
\end{tabular}


The likelihood-to-buy questions framed in a conjoint design were developed to assess consumer response to four attributes: species, price, insect management strategy, and $\mathrm{eco}^{-}$ friendly production practices. We used four different plant species in each category, with four prices, four insect management strategies (without definition or explanation), and four eco-friendly production practices [also without definition or explanation (Table 1)].

Although all 256 permutations of attributes could have been presented to respondents, we developed a fractional factorial conjoint design of 16 combinations of hypothetical ornamental plant products for the survey to reduce time investment (Chrzan and Orme, 2000) and respondent fatigue. Fractional factorial design improves experiment efficiency by using only a fraction of the attribute combinations in experiments while retaining the ability to assess all attributes in the complete design. The images for the conjoint questions were shown to the participants before asking them any other questions (Fig. 1). Species included in this study were chosen based on widely known and commonly available plants in the floriculture industry. Although these species and cultivars may not be the best food source for bees and other pollinators, they are economically important to plant producers. In addition, commercial growers may be treating these species with neonicotinoid or other classes of insecticides during plant production, which may leave residue in the flower's pollen depending on application rate and timing. The images shown in the survey were taken by the researchers or colleagues and used with their permission. Price points were chosen based on the national market price of similar products in different types of retail outlets in 2014. Insect management strategies and eco-friendly production practices were based on the researcher's observations of potential new marketing terminology.

Data anAlysis. Conjoint analysis was conducted in SAS (version 9.3; SAS Institute, Cary, NC) using PROC TRANSREG. Means of coefficients and relative importance across respondents were analyzed in PROC GLM for significant differences between attributes using Tukey's honestly significant test with $P=0.05$ as a maximum value of significance. Frequency data were analyzed for differences using Wilcoxon-Mann-Whitney (PROC

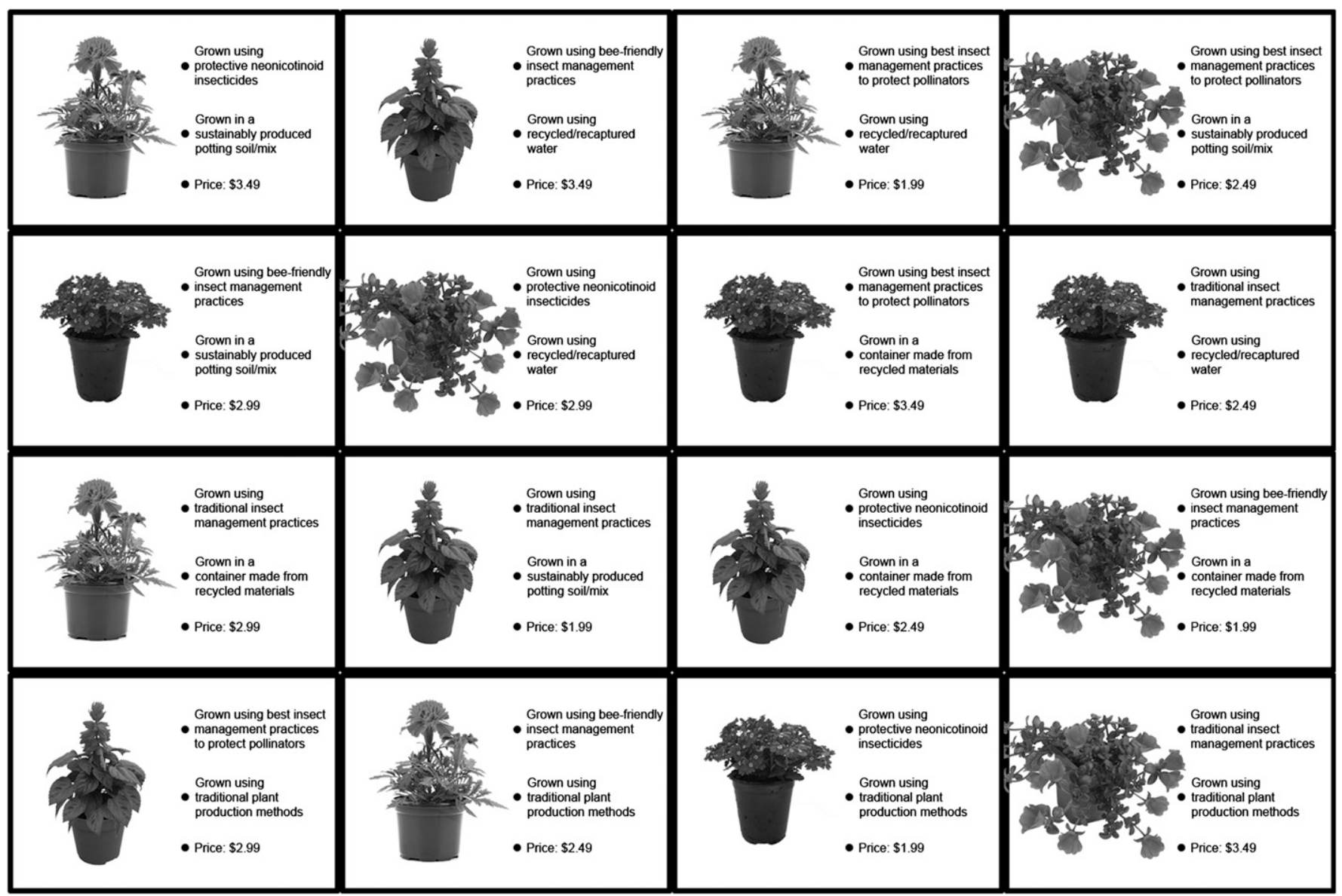

Fig. 1. Conjoint pictures shown to respondents in order from left to right, top to bottom in an Internet survey that queried consumers (who had purchased live plants in the past 12 months) perspectives on eco-friendly ornamental plant production practices in combination with a variety of insect management practices $(n=1555)$. Respondents were shown each picture individually in order and asked to rate each picture on a scale of 1 (very unlikely) to 5 (very likely) in terms of how likely they would be to purchase this flowering ornamental plant in a 4 -inch $(10.2 \mathrm{~cm})$ pot intended for use in the landscape at the given price and production method. 
NPARIWAY). Likert scale questions were analyzed for differences using PROC GLM and comparisons were performed using least square means with $P=0.05$ as a maximum value of significance.

Demographics. A total of 1555 consumers completed the survey (Table 2). The average age of consumers at the time of the survey was 49.4 years old, and gender distribution was roughly half female and half male. Nearly two-thirds (64.6\%) of participants had some college, an

\section{Results and discussion}

associate's degree, or a bachelor's degree. More than half $(54.1 \%)$ resided in suburban areas and about half $(53.7 \%)$ had a household income of $\$ 20,000$ to $\$ 79,999$ in 2014 . Every state was represented (data not shown).

Characteristics of insect MANAGEMENT PRACTICES. Over half $(55 \%)$ and nearly half $(48.2 \%)$ of the participants felt that "bees are not harmed" or "better for the environment," respectively, was a characteristic of bee-friendly insect management practices (Table 3). More than $30 \%$ also felt that "environmentally

Table 2. Demographical characteristics of participants in the Internet survey that queried consumers (who had purchased live plants in the past 12 mo.) perspectives on eco-friendly ornamental plant production practices in combination with a variety of insect management practices $(n=1555)$.

\begin{tabular}{|c|c|}
\hline Demographic & Mean no. or frequency \\
\hline Adults in household [no. (SE)] & $1.5(0.03)$ \\
\hline Children in household [no. (SE)] & $0.7(0.03)$ \\
\hline Age at the time of survey [years (SE)] & $49.4(0.43)$ \\
\hline \multicolumn{2}{|l|}{ Gender $[$ no. $(\%)]$} \\
\hline Female & $788(50.5)$ \\
\hline Male & $771(49.5)$ \\
\hline \multicolumn{2}{|l|}{ Ethnicity [no. (\%)] } \\
\hline African American & $75(4.6)$ \\
\hline Asian & $59(3.6)$ \\
\hline Hispanic & $103(6.4)$ \\
\hline Native American & $29(1.8)$ \\
\hline Pacific Islander & $0(0.0)$ \\
\hline White/Caucasian & $1,345(82.9)$ \\
\hline Other & $11(0.7)$ \\
\hline \multicolumn{2}{|l|}{ Education $[$ no. $(\%)]$} \\
\hline Less than high school & $14(0.9)$ \\
\hline High school/GED ${ }^{z}$ & $249(16)$ \\
\hline Some college & $341(21.9)$ \\
\hline 2 -year college degree & $164(10.5)$ \\
\hline 4-year college degree & $501(32.2)$ \\
\hline Master's degree & $204(13.1)$ \\
\hline Professional degree $(\mathrm{JD}, \mathrm{MD})^{\mathrm{z}}$ & $58(3.7)$ \\
\hline Doctoral degree & $25(1.6)$ \\
\hline \multicolumn{2}{|l|}{$\operatorname{Area}[$ no. $(\%)]$} \\
\hline Metropolitan region & $376(24.8)$ \\
\hline Rural region & $319(21.1)$ \\
\hline Suburban region & $818(54.1)$ \\
\hline \multicolumn{2}{|l|}{ Income $[$ no. $(\%)]$} \\
\hline Less than $\$ 19,999$ & $105(6.8)$ \\
\hline$\$ 20,000-\$ 39,999$ & $300(19.4)$ \\
\hline$\$ 40,000-\$ 59,999$ & $270(17.4)$ \\
\hline$\$ 60,000-\$ 79,999$ & $262(16.9)$ \\
\hline$\$ 80,000-\$ 99,999$ & $202(13.0)$ \\
\hline$\$ 100,000-\$ 119,999$ & $160(10.3)$ \\
\hline$\$ 120,000-\$ 139,999$ & $76(4.9)$ \\
\hline$\$ 140,000-\$ 159,999$ & $69(4.5)$ \\
\hline$\$ 160,000-\$ 179,999$ & $25(1.6)$ \\
\hline$\$ 180,000-\$ 199,999$ & $30(1.9)$ \\
\hline$\$ 200,000$ or more & $51(3.3)$ \\
\hline
\end{tabular}

${ }^{\mathrm{z}} \mathrm{GED}=$ General Educational Development certification, JD = Juris Doctorate, $\mathrm{MD}=$ Doctor of Medicine. friendly," "use of products without bee toxicity," "safer for humans," and "plants that attract bees" were additional characteristics. The latter characteristic ("plants that attract bees") indicated a continued confusion about the plant production practice vs. the plant itself (as a pollinator food source) as the term was also associated with bee-friendly in Wollaeger et al. (2015). About half $(50.9 \%)$ and roughly onethird $(33.8 \%)$ of participants characterized traditional insect management practices as "pesticides are used" and "insecticides are used," respectively. About two-fifths (41.3\%) of participants characterized best insect management practices to protect pollinators as "bees are not harmed," whereas more than $30 \%$ of participants agreed that "better for the environment," "use of products without bee toxicity," and "environmentally friendly" also characterized this practice. Almost half $(44.8 \%)$ of the participants answered "I do not know" when asked to characterize insect management practices that use protective neonicotinoid insecticides. The broad demographic based represented by respondents in this study and its consistency with previous findings (Wollaeger et al., 2015) indicates that the lack of understanding surrounding the word "neonicotinoid" is not associated with a particular demographic segment and may be extrapolated to all American consumers.

When asked to rate various insect management plant production practices on a scale of 1 (means something very negative) to 5 (means something very positive), consumer mean scores were positive (defined here as 3.5 to $5.0)$ for "plants grown using beefriendly insect management practices," "plants grown using insect management strategies that are safe for pollinators," "plants grown using best insect management practices to protect pollinators," and "plants grown using insect management practices that leaves no insecticide residue on the plant" (Table 4). All other production practices were neutral in meaning (defined here as 2.5 to 3.5).

IM PORTANCE OF PLANT ATTRIBUTES IN PURCHASING DECISIONS. Consumers ranked "the flowering plant has no plant damage" as the most important attribute [on a 7-point Likert scale of 1 (not at all important) to 7 (very important)] 
Table 3. The number and percentage of Internet survey participants who chose each trait in response to the question "Which of the following do you consider to be characteristic of plants that are grown using (one of the four pest management practices)? Choose all that apply." The Internet survey queried consumers (who had purchased live plants in the past 12 mo.) perspectives on eco-friendly ornamental plant production practices in combination with a variety of insect management practices $(n=1555)$. Traits are presented here in alphabetical order, but were presented to participants randomly.

\begin{tabular}{|c|c|c|c|c|}
\hline \multirow[b]{2}{*}{ Trait } & \multicolumn{4}{|c|}{ Pest management practice $[$ no. $(\%)]$} \\
\hline & $\begin{array}{c}\text { Bee-friendly insect } \\
\text { management } \\
\text { practices }\end{array}$ & $\begin{array}{c}\text { Traditional insect } \\
\text { management } \\
\text { practices }\end{array}$ & $\begin{array}{c}\text { Best insect management } \\
\text { practices to protect } \\
\text { pollinators }\end{array}$ & $\begin{array}{c}\text { Protective } \\
\text { neonicotinoid } \\
\text { insecticides }\end{array}$ \\
\hline A healthy appearing plant & 309 (19.9) & $218(14)$ & $321(20.6)$ & $154(9.9)$ \\
\hline Bees are not harmed & $855(55)$ & $155(10)$ & $642(41.3)$ & $178(11.4)$ \\
\hline Better for the environment & $749(48.2)$ & $171(11)$ & $591(38)$ & $222(14.3)$ \\
\hline Has no insects on the plant & $128(8.2)$ & $284(18.3)$ & $197(12.7)$ & $121(7.8)$ \\
\hline Hazardous for humans & $51(3.3)$ & $228(14.7)$ & $43(2.8)$ & $95(6.1)$ \\
\hline Higher price & $251(16.1)$ & $116(7.5)$ & $216(13.9)$ & $128(8.2)$ \\
\hline I do not know & $172(11.1)$ & $218(14)$ & $292(18.8)$ & $697(44.8)$ \\
\hline Inexpensive & $115(7.4)$ & $150(9.6)$ & $70(4.5)$ & $51(3.3)$ \\
\hline Insecticides are not used & $262(16.8)$ & $38(2.4)$ & $173(11.1)$ & $46(3)$ \\
\hline Marketing gimmick & $101(6.5)$ & $85(5.5)$ & $91(5.9)$ & $77(5)$ \\
\hline $\begin{array}{l}\text { No pesticide residue on } \\
\text { flowers and leaves }\end{array}$ & $260(16.7)$ & $50(3.2)$ & $220(14.1)$ & $63(4.1)$ \\
\hline No synthetic pesticide used & $224(14.4)$ & $54(3.5)$ & $216(13.9)$ & $59(3.8)$ \\
\hline Not environmentally friendly & $47(3)$ & $359(23.1)$ & $57(3.7)$ & $102(6.6)$ \\
\hline $\begin{array}{l}\text { Pesticide residue on flowers } \\
\text { and leaves }\end{array}$ & $65(4.2)$ & $364(23.4)$ & $72(4.6)$ & $111(7.1)$ \\
\hline Pesticides are not used & $411(26.4)$ & $120(7.7)$ & $308(19.8)$ & $111(7.1)$ \\
\hline Pesticides are used & $139(8.9)$ & $792(50.9)$ & $125(8)$ & $200(12.9)$ \\
\hline Plants not attractive to bees & $77(5)$ & $99(6.4)$ & $69(4.4)$ & $65(4.2)$ \\
\hline Plants that attract bees & $488(31.4)$ & $138(8.9)$ & $320(20.6)$ & $122(7.8)$ \\
\hline $\begin{array}{l}\text { Use of products that are } \\
\text { toxic to bees }\end{array}$ & $57(3.7)$ & $301(19.4)$ & $67(4.3)$ & $120(7.7)$ \\
\hline $\begin{array}{l}\text { Use of products without } \\
\text { bee toxicity }\end{array}$ & $605(38.9)$ & $121(7.8)$ & $498(32)$ & $133(8.6)$ \\
\hline Use of synthetic pesticides & $61(3.9)$ & $319(20.5)$ & $73(4.7)$ & $142(9.1)$ \\
\hline Worse for the environment & $33(2.1)$ & $315(20.3)$ & $38(2.4)$ & $95(6.1)$ \\
\hline
\end{tabular}

when considering a plant purchase (Table 5). This is consistent with previous reports (Wollaeger et al., 2015). Participants ranked the next five attributes as equally important and included a plant that was grown in a way to protect pollinators with as little pesticides as possible that left no pesticide residue on the leaves or flowers, but also had no insects on the plant. These results are consistent with popularly held belief that customers perceive that any presence of insects, beneficial or not, reduces the quality of plants (Marsh and Gallardo, 2009).

The next most important characteristic was a low price, which was equally as important as plants grown in a sustainably produced potting soil mix as well as plants grown in a container made of recycled materials (Table 5). Price was more important than plants that were produced using bee-friendly practices or grown with recycled/recaptured water. Plants that were grown with no neonicotinoid products were rated second to last, which is probably a reflection on consumers lack of understanding of the word "neonicotinoid" (Wollaeger et al., 2015). Traditional insect management practices were the least desired attribute of any presented.

Conjoint analysis. Unlike the stated preferences for characteristics and attributes of plants in other questions, conjoint analysis extracts the relative importance of each attribute and level from the implied preference. 
Table 4. Mean score of Internet survey participants answer to the question "On a scale of 1 (means something very negative) to 5 (means something very positive), how would you label the meaning of the following plant production practices?" The Internet survey queried consumers (who had purchased live plants in the past $12 \mathrm{mo}$.) perspectives on eco-friendly ornamental plant production practices in combination with a variety of insect management practices $(n=1555)$.

\begin{tabular}{lc}
\hline Plant production practice & Score [mean (SE)] \\
\hline $\begin{array}{l}\text { Plants grown using bee-friendly } \\
\text { insect management practices }\end{array}$ & $4.18(0.02) \mathrm{a}^{\mathrm{z}}$ \\
$\begin{array}{l}\text { Plants grown using insect management } \\
\quad \text { strategies that are safe for pollinators }\end{array}$ & $4.14(0.02) \mathrm{ab}$ \\
$\begin{array}{l}\text { Plants grown using best insect management } \\
\quad \text { practices to protect pollinators }\end{array}$ & $4.06(0.021) \mathrm{b}$ \\
$\begin{array}{l}\text { Plants grown using insect management } \\
\text { practices that leaves no insecticide residue on the plant }\end{array}$ & $3.95(0.021) \mathrm{c}$ \\
$\begin{array}{l}\text { Plants grown using protective neonicotinoid insecticides } \\
\text { Plants grown using neonicotinoid insecticides }\end{array}$ & $3.31(0.024) \mathrm{d}$ \\
Plants grown using traditional insect management practices & $3.18(0.025) \mathrm{e}$ \\
${ }^{2}$ Means within a column followed by the same lowercase letter are not different by Tukey's honestly significant
\end{tabular}
difference $(P \leq 0.05)$.

Table 5. Mean response of Internet survey participants to the question "In thinking about your choices to buy flowering plants, how important are each of these to your purchase decision $(1=$ not at all important, $7=$ very important $)$ ?" The Internet survey queried consumers (who had purchased live plants in the past 12 mo.) perspectives on eco-friendly ornamental plant production practices in combination with a variety of insect management practices $(n=1555)$.

\section{Characteristic}

The flowering plant has no plant damage

The plant was grown in a way that protected pollinators

The flowering plant was grown using as little pesticides as possible

The flowering plant has no insects on it

The flowering plant has no pesticide residue on the leaves or flowers

The plant was grown in an environmentally friendly manner

Insects harmful to the plant were controlled by using beneficial insects

The plant has a low price

The plant was grown in a sustainably produced potting soil/mix

The plant was grown in containers made of recycled materials

The plant was produced using bee-friendly practices

Recycled/recaptured water was used to grow the plant

No neonicotinoid products were used to grow the plant

The plant was grown with traditional insect management strategies

${ }^{\mathrm{z}}$ Means within a column followed by the same lowercase letter are not different by Tukey's honestly significant difference $(P \leq 0.05)$.
The relative importance and partworth utility for each attribute (price, species, insect management practice, and eco-friendly production practice) in the conjoint study is shown in Table 6 . The part-worth utility was used to examine the order of importance of these factors to the respondents within the survey. Plant species accounted for $31.6 \%$ of the decision to

Response [mean (sE)]

$5.89(0.032) \mathrm{a}^{\mathrm{z}}$

$5.46(0.04) \mathrm{b}$

$5.4(0.04) \mathrm{b}$

$5.34(0.042)$ bc

$5.34(0.04)$ bc

$5.32(0.041)$ bc

$5.2(0.039) \mathrm{cd}$

$5.16(0.038)$ cde

$5.02(0.04) \mathrm{def}$

$4.97(0.043)$ ef $4.88(0.046) \mathrm{f}$ $4.82(0.046) \mathrm{fg}$ $4.65(0.045) \mathrm{g}$ $4.21(0.045) \mathrm{h}$ purchase the plant, followed by price $(25.1 \%)$, insect management strategy $(23.3 \%)$, and eco-friendly practices $(20.1 \%)$. This is similar to findings in Canada that showed consumers valued price ( $22 \%$ to $29 \%$ relative importance) over pest management practices $(22 \%$ to $25 \%$ relative importance) for greenhousegrown mums [Dendranthema $\times$ grandiflorum (Grygorczyk et al.,
2014)]. This finding was contrary to other research that showed that price was equally as important as species and insect management production practice for 4-inch outdoor ornamental bedding plants (Wollaeger et al., 2015). This present study, however, did demonstrate that the insect management strategy was indeed more important to consumers in the purchase decision compared with the selected eco-friendly production practices.

When considering all levels of each attribute, lower prices were preferred to higher prices. Although this may seem intuitive, this indicates the use of logic or rational reasoning by subjects when coming to a conclusion about their willingness to purchase the plants shown in the images. Among the four insect management strategies, the "traditional" insect control method was least preferred (had a lower part-worth score), whereas the term "bee-friendly" was the most preferred (had a higher part-worth utility score) and was more valuable to survey participants than "grown using best management practices to protect pollinators" and "grown using protective neonicotinoid insecticides." These results are consistent with those reported in Wollaeger et al. (2015) where consumers were willing to pay the most for "bee friendly" and the least for "traditional" insect management practices. Of the eco-friendly plant production practices, grown using recycled/recaptured water, as well as grown in a sustainable potting mix were equally preferred over plants grown in pots made from recycled materials. "Traditional" eco-friendly production methods were least preferred.

To put these results into a monetary context, the difference between the lowest and the highest price 4-inch pot was $\$ 1.50$ and the price utility difference was 0.495 [the minimum of the price utilities $(-0.221)$ subtracted from the maximum of the price utilities $(0.274)]$. Therefore, the change in the part-worth means score was worth $\$ 3.03$ (\$1.50/0.495). We can conclude that plants labeled as "grown using bee-friendly insect management practices" are worth $\$ 0.26, \$ 0.26$, $\$ 0.89$, and $\$ 1.15$ more than plants labeled as "grown in a sustainably produced potting soil/mix," "grown using recycled/recaptured water," "grown using protective neonicotinoid insecticides," and "grown using traditional insect management practices," 
Table 6. Mean part-worth and relative importance scores for a conjoint analysis (price, species, insect management practices, and eco-friendly production practices) from an Internet survey that queried consumers (who had purchased live plants in the past 12 mo.) perspectives on eco-friendly ornamental plant production practices in combination with a variety of insect management practices $(n=1555)$.

\begin{tabular}{|c|c|c|}
\hline Attribute & Part-worth scores $^{\mathrm{z}}[$ mean (SE)] & Relative importance scores ${ }^{y}[$ mean $(\mathrm{sE})]$ \\
\hline Price & & $25.09(0.421) b^{x}$ \\
\hline$\$ 1.99$ & $0.274(0.0111) \mathrm{a}^{\mathrm{x}}$ & \\
\hline$\$ 2.99$ & $-0.057(0.0072) \mathrm{fg}$ & \\
\hline$\$ 3.49$ & $-0.221(0.0108) \mathrm{h}$ & \\
\hline Species & & $31.57(0.580) \mathrm{a}$ \\
\hline Salvia & $-0.069(0.012) \mathrm{fg}$ & \\
\hline Verbena & $0.115(0.0125) \mathrm{c}$ & \\
\hline Insect management strategy & & $23.26(0.446) c$ \\
\hline $\begin{array}{l}\text { Grown using traditional insect } \\
\text { management practices }\end{array}$ & $-0.200(0.0119) \mathrm{h}$ & \\
\hline $\begin{array}{l}\text { Grown using protective neonicotinoid } \\
\text { insecticides }\end{array}$ & $-0.112(0.0116) \mathrm{g}$ & \\
\hline Eco-friendly practices & & $20.08(0.304) \mathrm{d}$ \\
\hline $\begin{array}{l}\text { Grown in a container made from } \\
\text { recycled materials }\end{array}$ & $-0.020(0.0073) \mathrm{def}$ & \\
\hline $\begin{array}{l}\text { Grown in a sustainably produced } \\
\text { potting soil/mix }\end{array}$ & $0.094(0.0077) \mathrm{c}$ & \\
\hline Grown using recycled/recaptured water & $0.095(0.0084) \mathrm{c}$ & \\
\hline $\begin{array}{l}\text { Grown using traditional plant production } \\
\text { methods }\end{array}$ & $-0.170(0.0103) \mathrm{h}$ & \\
\hline
\end{tabular}

${ }^{2}$ Part-worth scores having a positive and a negative value indicate consumers had a positive or negative preference for the indicated trait, respectively. Larger absolute values indicate a stronger preference than smaller absolute values.

${ }^{y}$ Relative importance scores having larger values indicate consumers placed a higher value on that attribute than those attributes with lower scores.

${ }^{x}$ Means within a column followed by the same lowercase letter are not different by Tukey's honestly significant difference $(P \leq 0.05)$.

respectively. This perceived price premium of $\$ 1.15$ for "bee friendly" plants compared with "traditionally grown" plants was similar to the previously reported $\$ 0.96$ price premium (Wollaeger et al., 2015). In addition, plants labeled as "grown using best insect management practices to protect pollinators" are worth $\$ 0.10, \$ 0.10, \$ 0.73$, and \$0.99 more than plants labeled as "grown in a sustainably produced potting soil/mix," "grown using recycled/ recaptured water," "grown using protective neonicotinoid insecticides," and "grown using traditional insect management practices," respectively.

Among the plant species, verbena (Verbena $\times$ bybrida) was preferred more than moss rose (Portulaca grandiflora), whereas marigold (Tagetes erecta) and salvia (Salvia splendens) were equally preferred the least. The response of participants to preferring marigolds least is interesting in that the U.S. Department of Agriculture (USDA) tracks sales of the largest segments of floriculture products and marigolds are one of those segments having sold 3.6 million flats and 10.4 million potted plants in 2014 (USDA, 2015).

\section{Conclusions}

Consumers evaluate many factors when buying plants. Among those factors are the insect management practices and environmental impact of plant production, if advertised by the retailer. When asked pointedly, consumers want perfect plants ("The flowering plant has no plant damage" mean $=5.89$ ) at the lowest possible price (lowest price had the highest mean part-worth score in the conjoint analysis). Saliency refers to a topic or concept that is "at the top of mind" and perhaps one reason for the higher mean relative importance of insect management strategy over ecofriendly production practices (lowest relative importance) was the considerable publicity on the topic of bees and bee health. Plant species continues to be the key driver of the purchase decision, whereas price and other attributes are of lesser relative importance. Consumers' knowledge of "bee friendly" production practices continues to be inaccurate as evidenced by the high percentage of subjects agreeing that that specific production practice makes plants more attractive to bees. Media may be drawing attention to the use of neonicotinoid insecticides but our data shows that the publicity has not been successful in educating the general public with scientifically accurate information on the definition of "bee friendly" insect management practices. The need for sensitivity to the environment appears to be less an issue with consumers than insect management practices as evidenced by the lower relative importance of eco-friendly practices compared with insect management strategies. Therefore, growers and retailers who educate their customers and promote their current practices may elevate the perceived value of these more sustainable production methods. 
Also, the study sought to integrate a more holistic set of attributes with the inclusion of eco-friendly practices. We observed that, with the addition of those practices, the relative importance of price was less than in Wollaeger et al. (2015). The complexity of plant attributes challenges researchers to make the choices of extrinsic characteristics as broad and as realistic as possible. However, no singular consumer study presents the definitive case for what consumers actually see in the marketplace. Researchers should continue to provide multiple attributes in studies evaluating willingness to pay for products to capture a more complete perspective.

No study is without its limitations. Here, the online sample and survey methods in general are not considered by all to be accurate reflections of consumer behavior, while there is some evidence to support the notion that survey research is reflective of actual consumer behavior (Yue et al., 2010). Another limitation of the study may be that our recruited subjects were responding to selected stimuli and may not have responded in an identical manner had other plants, production methods, definitions, or explanations been provided. We do believe, however, that the data support our conclusions.

Finally, the authors recommend the honest and ethical use of the term "bee friendly practices" in labeling. Although consumers are neither accurate nor unanimous in their interpretation of this phrase, the data suggest it is helpful (and potentially more profitable) for plant marketers to use the phrase in the identification of plant production practices that may cause little to no harm to bee populations (given the current level of understanding about pest management strategies and tools). Future marketing efforts made by companies who use the phrase may also help to educate the public at large about the meaning of "bee friendly" and the details that might be of interest to some customers. This information might be made available on a website or other locale where interested persons might develop a more accurate perception of "bee friendly" pest management tools and practices.

\section{Literature cited}

Behe, B.K., B.L. Campbell, J.H. Dennis, C.R. Hall, R. Lopez, and C. Yue. 2010. Gardening consumer segments vary in ecopractices. HortScience 45:1475-1479.

Behe, B.K., B.L. Campbell, C.R. Hall, H. Khachatryan, J.H. Dennis, and C. Yue. 2013. Consumer preferences for local and sustainable plant production characteristics. HortScience 48:200-208.

Behe, B., J. Hardy, S. Barton, J. Brooker, T. Fernandez, C. Hall, J. Hicks, R. Hinson, P. Knight, R. McNiel, T. Page, B. Rowe, C. Safley, and R. Schutzki. 2005a. Landscape plant material, size, and design sophistication increase perceived home value. J. Environ. Hort. 23:127-133.

Behe, B.K., R.M. Walden, M. Duck, B. Cregg, K. Kelley, and R.D. Lineberger. 2005 b. Consumer preferences for and cost of production of tabletop Christmas trees. HortScience 40:409-412.

Chrzan, K. and B. Orme. 2000. An overview and comparison of design strategies for choice-based conjoint analysis 20 Nov. 2015. <https://www. sawtoothsoftware.com/download/ techpap/desgncbc.pdf $>$.

Doublet, V., M. Labarussias, J.R. de Miranda, R.F.A. Moritz, and R.J. Paxton. 2015. Bees under stress: Sublethal doses of a neonicotinoid pesticide and pathogens interact to elevate honey bee mortality across the life cycle. Environ. Microbiol. 17:969983.

Getter, K.L. and B.K. Behe. 2013. Consumer willingness to purchase Impatiens walleriana alternatives. HortScience 48:1370-1377.

Goulson, D. 2013. An overview of the environmental risks posed by neonicotinoid insecticides. J. Appl. Ecol. 50:977-987.

Goulson, D., E. Nicholls, C. Botías, and E.L. Rotheray. 2015. Bee declines driven by combined stress from parasites, pesticides, and lack of flowers. Science 347:1255957.

Grygorczyk, A., J. Turecek, and I. Lesschaeve. 2014. Consumer preferences for alternative pest management practices used during production of an edible and a nonedible greenhouse crop. J. Pest Sci. 87:249-258.

Hall, C., B. Campbell, B. Behe, C. Yue, J. Dennis, and R. Lopez. 2010. The appeal of biodegradable packaging to floral consumers. HortScience 45:583-591.
Hartigan, J.A. 1975. Clustering algorithms. Wiley, New York, NY.

Jetter, K. and T.D. Paine. 2004. Consumer preferences and willingness to pay for biological control in the urban landscape. Biol. Control 30:312-322.

Kuhfeld, W.F. 2010. Marketing research methods in SAS. SAS Inst., Cary, NC.

Marsh, T.L. and K. Gallardo. 2009. Adopting biological control for ornamental crops in greenhouses. CAB Rev. Perspectives Agr. Veterinary Sci. Nutr. Natural Resources 4:1-9.

Olson, D.L., J.R. Nechols, and C.W. Marr. 1995. Consumer's preference for insecticide-free pumpkins in eastern Kansas. HortTechnology 5:274-276.

Pisa, L.W., V. Amaral-Rogers, L.P. Belzunces, J.M. Belzunces, J.M. Bonmatin, C.A. Downs, D. Goulson, D.P. Kreutzweiser, C. Krupke, M. Liess, M. McField, C.A. Morrissey, D.A. Noome, J. Settele, N. Simon-Delso, J.D. Stark, J.P. van der Sluijs, H. van Dyck, and M. Wiemers. 2015. Effects of neonicotinoids and fipronil on non-target invertebrates. Environ. Sci. Pollution Res. 22:68-102.

U.S. Department of Agriculture. 2015. Floriculture crops 2014 summary. 14 July 2015. <http://usda.mannlib.cornell. edu/usda/current/FlorCrop/FlorCrop06-04-2015.pdf>.

van Gaasbeek, A.F. and V.C. Bouwman. 1991. Conjoint analysis in market research for horticultural products. Acta Hort. 295:121-125.

Wollaeger, H.M., K.L. Getter, and B.K. Behe. 2015. Consumer preferences for traditional, neonicotinoid-free, beefriendly, or biological control pest management practices on floriculture crops. HortScience 50:721-732.

Yue, C., C.R. Hall, B.K. Behe, B.L. Campbell, J.H. Dennis, and R.G. Lopez. 2010. Are consumer willing to pay more for biodegradable containers than for plastic ones? Evidence from hypothetical conjoint analysis and non-hypothetical experimental auctions. J. Agr. Appl. Econ. 42:757-772.

Zagaden, Y., B.K. Behe, and R. Gough. 2008. Consumer preferences for native plants in Montana residential landscapes and perceptions for naturalistic designs. J. Environ. Hort. 26:109-114. 